\title{
Attentional capacity is undifferentiated: Concurrent discrimination of form, color, and motion
}

\author{
DALE KATHLEEN LEE, CHRISTOF KOCH, and JOCHEN BRAUN \\ California Institute of Technology, Pasadena, California
}

\begin{abstract}
We report a series of experiments on the concurrent discrimination of form, color, and motion attributes. All tasks involved joint discrimination of attributes, and positions and were highly demanding of attention. We quantified interference between concurrent discriminations by establishing the attentionoperating characteristic. Interference was indistinguishable for similar and dissimilar task combinations (form-form, color-color, motion-motion, and color-form, color-motion, motion-color, and motionform, respectively). These results suggest strongly that different visual discriminations draw on the same attentional capacity-in other words, that the capacity of visual attention is undifferentiated.
\end{abstract}

When two visual objects are presented briefly and simultaneously, observers often readily discriminate one object, but find it next to impossible to discriminate both (Bonnel \& Miller, 1994; Bonnel \& Prinzmetal, 1998; Bonnel, Stein, \& Bertucci, 1992; Braun \& Julesz, 1998; Braun \& Sagi, 1991; Duncan, 1984; Duncan, Ward, \& Shapiro, 1994; Fisher, 1984; Kahneman \& Treisman, 1984; Kleiss \& Lane, 1986; Sperling \& Melchner, 1978; Ward, Duncan, \& Shapiro, 1996). The difficulty of simultaneously discriminating two visual objects is thought to reflect the "limited capacity" of visual attention (e.g., Broadbent, 1971; Kahneman, 1973; Neisser, 1967). Here we ask whether attentional capacity limitations depend on the similarity of the discriminations in questionspecifically, whether it depends on whether they involve similar or dissimilar stimulus dimensions (e.g., form, color, or motion).

In nonhuman primates, neuronal sensitivities to stimulus dimensions such as form, color, or motion are concentrated in different visual cortical areas (Felleman \& Van Essen, 1991; Van Essen \& Gallant, 1994), and functional imaging studies have shown similar functional specializations in the visual cortex of humans (Corbetta, Miezin, Dobmeyer, Shulman, \& Petersen, 1990; Corbetta, Shulman, Miezin, \& Petersen, 1995; Van Essen \& Drury, 1997). More than 20 years ago, it was suggested that dimensions such as form, color, and motion are processed by separate subsystems ("perceptual analyzers") and that simultaneous visual discriminations should be problematic only if they engage the same subsystem, but not if they involve different subsystems (Allport, 1971;

This research was supported by grants from NIMH, ONR, Sloan Foundation for Theoretical Biology, and NSF Center for Neuromorphic Engineering. We are extremely grateful to Terry Sejnowski for giving us access to laboratory facilities. Correspondence should be addressed to J. Braun, California Institute of Technology, Biology 139-74, Pasadena, CA 91125 (e-mail: achim@klab.caltech.edu).
Treisman, 1969). In other words, two form discriminations or two color discriminations should interfere severely, but one form and one color discrimination should not. A more abstract formulation of this point of view is that attentional capacity is "differentiated" (Sperling \& Dosher, 1986) in that discriminations concerning different dimensions draw at least in part on different attentional capacities and are thus less liable to interfere than discriminations concerning the same stimulus dimension. Many current theories of attention are sympathetic to this position (e.g., Kinsbourne, 1981; Pashler, 1997).

Of course, the fact that visual cortex is to some degree functionally specialized does not mean that attentional capacity is necessarily differentiated. It remains to be seen whether the subsystems that process different stimulus dimensions are sufficiently independent to allow simultaneous discrimination of, say, the form of one visual object and the color of another. In fact, Duncan and colleagues have argued at length for a contrary point of view (Desimone \& Duncan, 1995; Duncan, Humphreys, \& Ward, 1997). In their view, the neural responses to different visual objects compete and "a gain in activity for one object is accompanied by a loss in activity for others" (p. 255). Although the response to each object involves multiple subsystems, competition is integrated "as a winning object emerges in one [sub]system, it tends also to become dominant in others" (Duncan, Humphreys, \& Ward, 1997, p. 255). Due to the strong interdependence of the subsystems that process different stimulus dimensions, discriminating the form and color of two visual objects, respectively, should be just as difficult as discriminating the forms of both. In this view, therefore, attentional capacity is "undifferentiated."

The question as to whether visual attention is differentiated or undifferentiated can be approached in a number of ways. One approach is to study the discrimination of different attributes of the same object (e.g., color and form) and to take advantage of spontaneous fluctuations 
in the allocation of attention to the target attributes. If success on one attribute and success on the other are positively correlated, one may conclude that both attributes are subject to the same fluctuations and, therefore, that attention is undifferentiated (Bonnel \& Prinzmetal, 1998; Monheit \& Johnston, 1994). If attention were differentiated, one might expect the two attributes to be subject to independent fluctuations and therefore to exhibit no such correlation (Isenberg, Nissen, \& Marchak, 1990; Nissen, 1985). The drawback of this approach is that the observed correlations are small and their existence difficult to establish (Johnston, Ruthruff, \& Monheit, 1997; van der Velde $\&$ van der Heijden, 1997).

A more promising approach is to study the discrimination of two separate objects (Duncan, 1993; Sperling \& Dosher, 1986). When attention is divided between two objects, a practiced observer is generally able to "trade off" performance on one object against performance on the other. In other words, the observer can alter the division of attention and fare better with one task and worse with the other. For some tasks, such voluntary changes in attentional allocation produce large changes in performance, in some cases from chance to ceiling. As a result, the dependence of the performance of one task on performance of the other ("tradeoff function") is a sensitive measure of the extent to which two tasks compete for attention. Armed with this measure, we can determine whether visual attention is differentiated or undifferentiated. If attention is differentiated, two tasks should interfere less when different attributes (e.g., color and form) than when the same attributes are discriminated (e.g., color and color, or form and form). If attention is undifferentiated, however, the discrimination of same attributes and different attributes should lead to the same degree of interference.

A complicating factor is that the discrimination of some stimulus attributes requires more attentional capacity than that of others. Using concurrent tasks, we previously found that discrimination of letter shape requires essentially full attention, while discrimination of triangular or circular form and the discrimination of orientation are significantly less demanding of attention, and the discrimination of color is essentially free of attentional cost (Braun, 1994, 1998; Braun \& Julesz, 1998). A similar ranking of attentional cost emerges from studies of visual search: Search for a unique letter shape exhibits steeper search slopes than search for a unique orientation or color. In general, the attributes whose discrimination results in greater interference between concurrent tasks are also those for which visual search exhibits steeper "search slopes" (see, e.g., Enns \& Rensink, 1990; Julesz, 1981, 1984; Treisman \& Gelade, 1980; Treisman \& Gormican, 1988; Treisman \& Souther, 1985; Wolfe, 1994). Whether attentional costs of different discriminations are distributed on a continuum, or whether the distribution is bimodal with some discriminations being indeed free of attentional cost, is a matter of continuing debate (see, e.g., Braun, 1998; Braun \& Julesz, 1998; Joseph, Chun, \& Nakayama, 1997). What matters here is that the undis- puted and sizable differences in attentional cost need to be taken into account in any quantitative comparison of similar and dissimilar task combinations.

A number of previous studies have compared similar and dissimilar task combinations, but with less than conclusive results. Duncan and colleagues have studied the discrimination of form attributes (letter form, size, orientation, length), surface attributes (color, brightness, texture), and motion attributes (left- or rightward motion) in various combinations (Duncan, 1993; Duncan \& Nimmo-Smith, 1996; Ward, Duncan, \& Shapiro, 1997). For each task combination, interference was assessed by comparing performance of each task alone with performance of both tasks together. In general, similar and dissimilar task combinations exhibited comparable degrees of interference-that is, comparable differences between performance alone and performance together, although some dissimilar combinations (especially those involving color discrimination) exhibited little or no interference. Duncan and colleagues concluded that all discriminations, with the possible exception of color, draw on the same attentional capacity. However, the degree of interference encountered even with similar task combinations was small and varied substantially between different task combinations. (The difference between performance together and performance alone ranged from $\approx 5 \%$ to $\approx 15 \%$, where chance performance is $50 \%$ ).

The present study modified this paradigm in order to obtain more conclusive results. First, we maximized task interference by using discriminations with high attentional cost. We increased attentional cost by increasing positional uncertainty and by requiring the joint discrimination of form, color, or motion and position. (As a result, the difference between performance together and performance alone ranges from $\approx 28 \%$ to $\approx 42 \%$.) Second, we established a complete tradeoff function for each task combination. This allowed us to quantify the degree of interference in each case and made it easier to relate our findings to the substantial theoretical literature on "divided" attention (e.g., Navon \& Gopher, 1979; Norman \& Bobrow, 1975; Sperling \& Dosher, 1986; Sperling \& Melchner, 1978).

We previously investigated concurrent tasks of high attentional cost in two studies (Braun, 1994; Braun \& Julesz, 1998), and concurrent tasks of lower attentional cost in several other studies (Ben-Av, Sagi, \& Braun, 1992; Braun, 1994; Braun \& Sagi, 1990, 1991). In every one of these studies, perceptual masking was a critical aspect of the design, since without masking one cannot be sure that the relevant visual information is indeed processed concurrently.

\section{METHOD}

\section{Equipment and Procedure}

Stimuli were generated by a Silicon Graphics Indigo 2 workstation and displayed on a high-resolution color monitor $(1,280 \times$ 1,024 pixels, $3 \times 8$ bit RGB, $60-\mathrm{Hz}$ frame rate). Viewing was binocular, from a distance of about $120 \mathrm{~cm}$, resulting in a display of approximately $12.5^{\circ} \times 16^{\circ}$ of visual angle, with $1^{\circ}$ corresponding 
to 80 pixels. Background luminance was $26.6 \mathrm{~cd} / \mathrm{m}^{2}$, luminance of display elements was $28.4 \mathrm{~cd} / \mathrm{m}^{2}, 26.3 \mathrm{~cd} / \mathrm{m}^{2}$ (Subject D.K.L.), or $29.5 / \mathrm{m}^{2}$ (Subject S.H.), and $91.5 \mathrm{~cd} / \mathrm{m}^{2}$ for red, green, and white elements, respectively; the ambient illumination level was $\approx 3 \mathrm{~cd} / \mathrm{m}^{2}$. Subjects fixated a mark at the center of the screen and initiated trials by pressing the "space" key. After viewing a sequence of stimulus and mask displays (see below), they responded by pressing assigned keys on the computer keyboard. Incorrect responses were marked by auditory feedback.

Two subjects participated in the experiment. One was the first author (D.K.L.) and the other was a volunteer paid for her participation (S.H.). Subjects were well trained and performed 9 (Subject D.K.L.) and 15 (Subject S.H.) training sessions before data collection began. Both subjects were highly practiced and performed 234 (D.K.L.) and 240 (S.H.) blocks of 50 trials in $\approx 30$ sessions over the course of 4 months. Fourteen (D.K.L.) and 8 (S.H.) blocks of trials were rejected because of a significant response correlation and are not included in these totals (see below). Each session was dedicated to one particular experiment and included blocks of trials with all three instructions (central task only, peripheral task only, both central and peripheral tasks; see below for details). At least two sessions were dedicated to each experiment, allowing us to distinguish between the first session and subsequent sessions. In total, we collected between 26 and 52 blocks of trials per experiment and subject (on average $\approx 34$ blocks). These numbers include both single- and double-task blocks.

Performance of individual tasks was relatively stable and showed little or no improvement over time (see Results section). However, the performance of task combinations tended to improve somewhat between the first and subsequent sessions dedicated to a particular combination, as will be discussed.

\section{Stimuli and Tasks}

All displays featured a central and a peripheral component, which posed two independent visual tasks. Depending on instructions, subjects performed the central task, the peripheral task, or both. The central component consisted of five elements that appeared at five of seven possible central locations-polar coordinates $(r, \theta)=\left(0^{\circ}, 0^{\circ}\right)$, $\left(0.875^{\circ}, 0^{\circ}\right),\left(0.875^{\circ}, 60^{\circ}\right), \ldots,\left(0.875^{\circ}, 300^{\circ}\right)$, where $r$ is in degrees of visual eccentricity and $\theta$ is in degrees of polar angle. The peripheral component was a single element at one of eight locationspolar coordinates $(r, \theta)$ with $r=4.375^{\circ}$ and $\theta=0^{\circ}, 45^{\circ}, \ldots, 315^{\circ}$. Although different experiments and tasks involved different types of elements (form, color, and motion), only two alternative forms of any element type were used. Central tasks involved reporting whether one of the five elements differed from the other four or whether all five elements were the same. Peripheral tasks involved reporting which of the two alternative elements had been present. The particular elements used here were chosen in pilot experiments because they yielded comparable psychometric functions (similar performance at any given presentation time for form, color, and motion discrimination).

For form discrimination, we used randomly rotated white T- and L-shaped elements (Figure la). The central task was to inspect the five central forms and to report "same" (five Ts or five Ls) or "different" (four Ts and one L, or four Ls and one T). The peripheral task was to inspect the single peripheral element and to report "T" or "L."

For color discrimination, we used vertically bisected disks with red and green halves (Figure $1 \mathrm{~b}$ ). The colors were isoluminant (flicker photometry), and the color order was either green left and red right (GR), or red left and green right (RG). The central task was to inspect the five central disks and to report "same" (five RGs or five GRs) or "different" (four RGs and one GR, or four GRs and one $R G$ ). The peripheral task was to inspect the single peripheral disk and to report "GR" or "RG."

For motion discrimination, we used white "dumbbell" forms rotating around their center (Figure Ic). The angular velocity of each dumbbell was chosen randomly in the range from 1.5 revolutions per second (rps) to $3.5 \mathrm{rps}$, and the rotation was either clockwise $(\mathrm{CW})$ or counterclockwise $(\mathrm{CCW})$. The central task was to inspect the five central dumbbells and to report "same" (five CWs or five

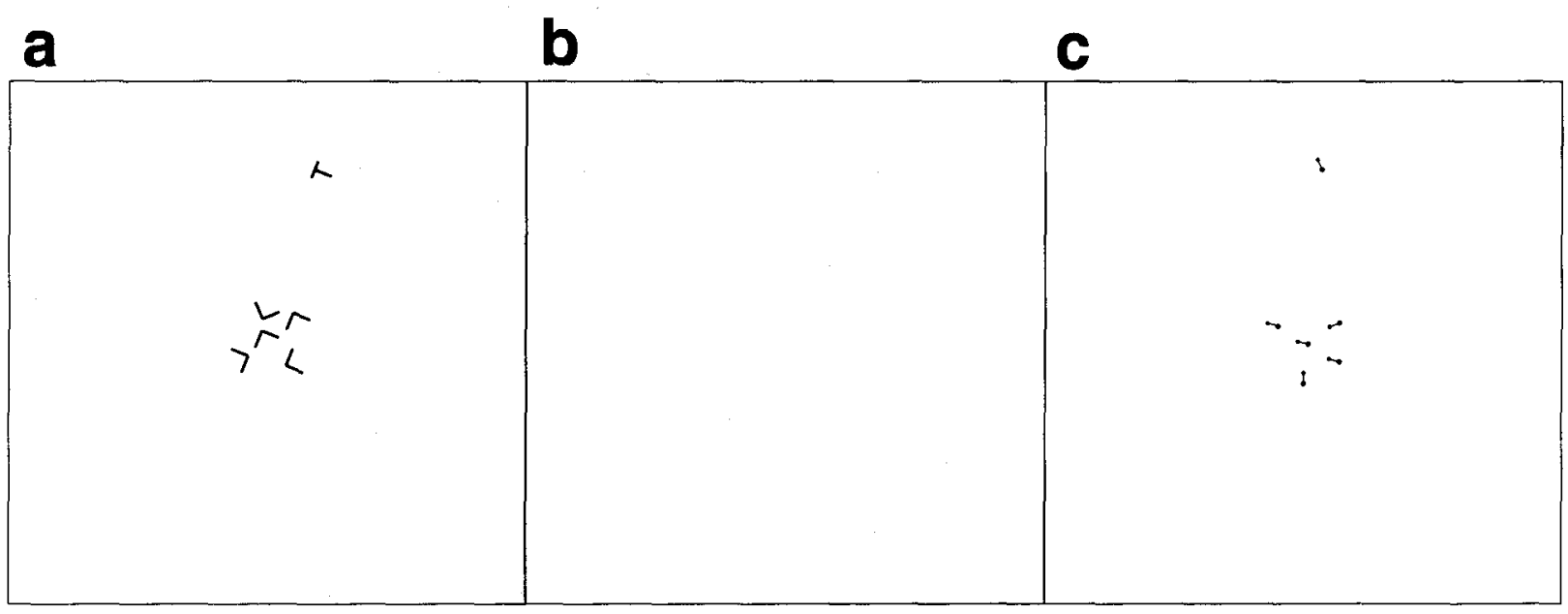

Figure 1. Examples of stimulus displays (schematic, drawn to scale). Central and peripheral form (a), color (b), and motion (c) discrimination. Form elements are $T$ - or $L-$-shaped and randomly rotated. Color elements are vertically bisected disks with red and green halves (indicated by hatching). Motion elements are dumbbell forms rotating either clockwise or counterclockwise around their center of gravity. In each case, there are five central elements and one peripheral element. With respect to the central elements, subjects reported whether all five elements exhibited the same form, coloring, or motion, or whether one element differed from the other four in form, coloring, or motion. With respect to the peripheral element, subjects identified the form, coloring, or motion. Central and peripheral elements were masked at appropriate (and usually different) times to obtain performance levels between $\approx 80 \%$ and $\approx 90 \%$ correct. 
CCWs) or "different" (four CWs and one CCW, or four CCWs and one $\mathrm{CW}$ ). The peripheral task was to inspect the single peripheral dumbbell and to report "CW" or "CCW."

For form and color discriminatıon, the visual persistence of stimulus elements was curtailed by masking, and stimulus onset asynchrony (SOA) was defined as the time between stimulus and mask onset. For motion discrimination, no masking was used, as there was no discernible visual persistence of dumbbell rotation. Here, SOA was defined as the time between stimulus onset and offset. For each task and subject, the SOA was adjusted individually to obtain a performance level of $\approx 80 \%$ correct when the task in question was carried out alone. Since elements had been chosen so as to yield comparable psychometric functions, SOAs for form, color, and motion discrimination were comparable. Central task SOAs ranged from 183 to $200 \mathrm{msec}$, and peripheral task SOAs from 67 to $100 \mathrm{msec}$. Note that due to the difference in SOA, peripheral display elements were masked earlier than central display elements.

All tasks in the present study were desıgned to place strong demands on attention. Although we have yet to study the issue systematically, we tentatively attribute the attention-demanding nature of the tasks in question to the fact that they involve judging the relative position of two features (of vertical and horizontal bars for the $\mathrm{T}$ - and L-shaped elements, of red and green for the bisected disks, and of the respective directions of motion of terminal points for the rotating dumbbells). In the terminology of Treisman, the tasks in question involve "conjoining" two features with two locations.

In spite of their somewhat complex nature, the discrimination tasks would have been "easy" had they concerned a single element at a known location: The necessary SOA to achieve $80 \%$ correct performance in discriminating a single $\mathrm{T}$ or $\mathrm{L}$ form, GR or RG disk, or $\mathrm{CW}$ or CCW rotatıng dumbbell at fixation can be as short as $40 \mathrm{msec}$. For the peripheral task, the necessary SOA was increased by visual eccentricity and positional uncertainty of the discriminated element. For the central task, this value was increased because the task involved more than one element and because these elements appeared at variable positions. Three elements would have been sufficient to obtain SOAs above $100 \mathrm{msec}$, but five elements were used in order to allow direct comparison with earlier work (Braun, 1994; Braun \& Julesz, 1998).

\section{Concurrent-Task Procedure}

Experiments were conducted and analyzed as described before (Braun, 1994; Braun \& Julesz, 1998). In some blocks of trials, subjects were instructed to concentrate on one task and ignore the other task, responding only once after each trial. This situation, which allows subjects to focus attention on one task, yields "single-task" performance. In other blocks of trials, subjects were instructed to perform both tasks and to respond twice after each trial. This situation, which forces subjects to divide attention between tasks, produces "double-task" performance. The order of responses has no noticeable effect on double-task performance (Braun \& Julesz, 1998). Subjects can voluntarily affect the way in which they divide attention between tasks, so that there is an entire family of possible double-task outcomes (one for every possible division of attention). To obtain the full range of outcomes, we used three variations of the basic double-task instruction: (1) "perform both tasks but give priority to the central task," (2) "perform both tasks but give priority to the peripheral task," and (3) "perform both tasks and give equal priority to both tasks." Note that the display remained the same for all instructions and always contained both central and peripheral components.

\section{Differentiated and Undifferentiated Capacity}

To formalize the distinction between differentiated and undifferentiated capacity, we treat attentional capacity as a divisible re- source. The empirical justification is that when observers attend to two tasks they can trade performance on one task off against performance on another. Thus we can nominally speak of the "fraction of attention" allocated to a particular task and can postulate a function that describes visual performance as this fraction increases from zero to unity ("performance-resource function" [PRF], Figure 2). Although PRFs cannot be observed directly, they are constrained by concurrent task results-that is, by how performance on one task depends on performance of the other (tradeoff function, or "attention operating characteristic" $[A O C]$ ). If attentional capacity is differentiated, the PRF of a given task will depend on the task with which it is paired. Dissimilar task pairs will result in more relaxed tradeoff curves and more rapidly saturating PRFs than will similar task pairs. If attentional capacity is undifferentiated, however, a given task will have the same PRF, regardless of which other task it is paired with. In this case, similar and dissımilar task pairs will result in the same PRFs.

\section{Theoretical PRF and AOC Curves}

To quantify concurrent task results, it is convenient to work with PRFs and AOCs in an explicit, analytical form. For example, one can assume sigmoidal PRFs of the form

$$
p(r)= \begin{cases}\frac{p(1)}{2}\left(\frac{2 r}{\alpha}\right)^{\beta} & \text { if } 0 \leq r \leq \frac{\alpha}{2} \\ p(1)-\frac{p(1)}{2}\left(\frac{2(\alpha-r)}{\alpha}\right)^{\beta} & \text { if } \frac{\alpha}{2}<r \leq \alpha, \\ p(1) & \text { if } \alpha<r \leq 1\end{cases}
$$

where $p(r)$ is performance (as a fraction of the interval between chance and ceiling, $p(r) \in[0,1]), r$ is the fraction of attention allocated to the task, $(r \in[0,1]), p(1)$ is performance with full attention (i.e., single-task performance), and $\alpha$ and $\beta$ are parameters. As illustrated in Figures $2 \mathrm{~b}$ and $2 \mathrm{c}$, the parameter $\alpha(0 \leq \alpha \leq 1)$ determines what fraction of attention suffices for optimal performance, and the parameter $\beta(\beta \geq 1)$ determines whether the relation between attention and performance is linear $(\beta=1)$, quadratic ( $\beta=$ 2), and so on.

Given two tasks $A$ and $B$, the AOC curve is obtained as the set of all $\left(p_{A}(r), p_{B}(1-r)\right)$ with $r \in[0,1]$ (Figures $2 \mathrm{a}-2 \mathrm{~d}$ ). By varying the PRF parameters $\alpha_{A}, \beta_{A}, \alpha_{B}$, and $\beta_{B}$, a wide range of different AOCs is obtained. If the tasks draw on pools of attentional resources that overlap only partially, optimal performance will be reached at some fraction of attention $\alpha_{A}$ and $\alpha_{B}$ that is smaller than unity (Figure 2a). As a result, there will be a certain performance range (smaller than the full range) in which the two tasks compete for attentional resources (Figure 2d). Specifically, Task A will compete for attention between $p_{A}\left(1-\alpha_{B}\right)$ and $p_{A}\left(\alpha_{A}\right)$, and Task B will compete between $p_{B}\left(1-\alpha_{A}\right)$ and $p_{B}\left(\alpha_{B}\right)$. The resulting AOC curve will lie above and to the right of the linear tradeoff line, but its precise form will depend on $\beta_{A}$ and $\beta_{B}$.

In the present series of experiments, the observed AOCs essentially follow the linear tradeoff line. This implies that optimal performance requires full attention $\left(\alpha_{A}=\alpha_{B}=1\right)$ and that the two PRFs are the same $\left(\beta_{A}=\beta_{B}\right)$. Note that the absolute value of $\beta$ remains undetermined.

\section{Contingency Analysis}

An important aspect of concurrent task experiments is whether the division of attention is consistent throughout a block of trials, or whether it varies across trials (Sperling \& Dosher, 1986). This can be decided by analyzing the joint probabilities of responding correctly and/or incorrectly on each task (Braun \& Julesz, 1998). If 
a
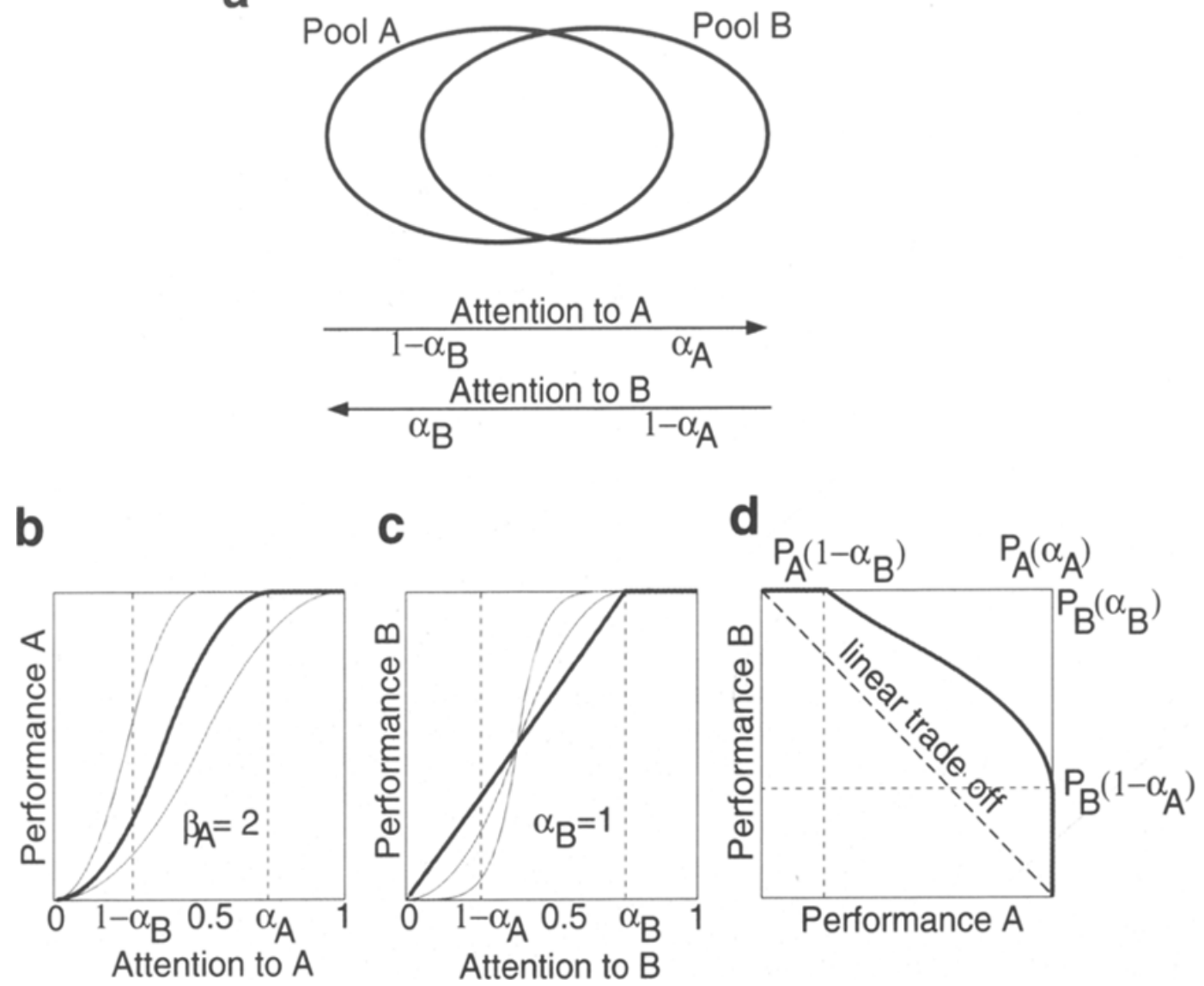

Figure 2. Attention-operating characteristic (AOC) and performance-resource functions (PRFs). (a) In the most general case, Tasks A and B draw on somewhat different "pools" of attentional resources. To generate AOCs, we assumed that attention can be divided arbitrarily between Tasks $A$ and $B$, but that attention to $A$ and attention to $B$ always sum to unity. (b) Performance $A$ as a function of the fraction of attention allocated to Task $A$. Three possible PRFs are shown, with $\alpha_{A}=0.5,0.75$, and 1.0 and $\beta_{A}=2.00$ (see Method section). (c) Performance $B$ as a function of attention allocated to Task $B$. Three possible PRFs are shown, with $\alpha_{B}=0.75$ and $\beta_{B}=$ 1, 2, and 5. (d) AOC resulting from the PRFs drawn with a thicker pen in (b) and (c) $\left(\alpha_{A}=0.75, \beta_{A}=2, \alpha_{B}=\right.$ $0.75, \beta_{B}=1$ ). Since $\alpha_{A}, \alpha_{B}<1$, the AOC lies above and to the right of the linear tradeoff line. Linear tradeoff is obtained if $\alpha_{A}=\alpha_{B}=1$ and $\beta_{A}=\beta_{B}$. Note that only (d) is experimentally observable.

the division of attention is constant, success or failure on one task will be independent of success or failure on the other. If the division varies, there will be a negative correlation.

To estimate the degree of attentional variation implied by an observed (negative) correlation, we can use the theoretical PRFs defined above. Given reasonable parameter values $\left(\alpha_{A}=\alpha_{B}=1, \beta_{A}=\right.$ $\beta_{B} \in[1,3]$ ), we can compute performance for any particular division of attention and, thus, the correlation resulting from a variable division of attention (e.g., $r=.43$ in $50 \%$ of the trials, and $r=.57$ in the remaining trials). The theoretical curves in Figure 6 are based on such a calculation.

\section{RESULTS}

\section{Similar Task Combinations}

The first series of experiments concerned concurrent performance of similar task pairs. Three pairs of tasks were investigated: central and peripheral discrimination of form, color, and motion, respectively. These experi- ments permit us to quantify the attentional cost of the tasks involved.

The results, shown in Figure 3, were comparable for both subjects and all task combinations. Each subject performed between 26 and 52 blocks of 50 trials on each task combination (average $\approx 34$ blocks). Generally, doubletask performance was inferior to single-task performance. Whenever double-task performance of one task approached the single-task level, double-task performance of the other task approached chance. Indeed, double-task performance was characterized by a roughly linear tradeoff between tasks: When either task was performed at its best, the other task was performed at chance, and any improvement in the performance of one task was at the expense of a reduction in the performance of the other. In some blocks of trials, double-task performance was well below the linear tradeoff line, suggesting that subjects did not efficiently allocate attention (in the sense that 

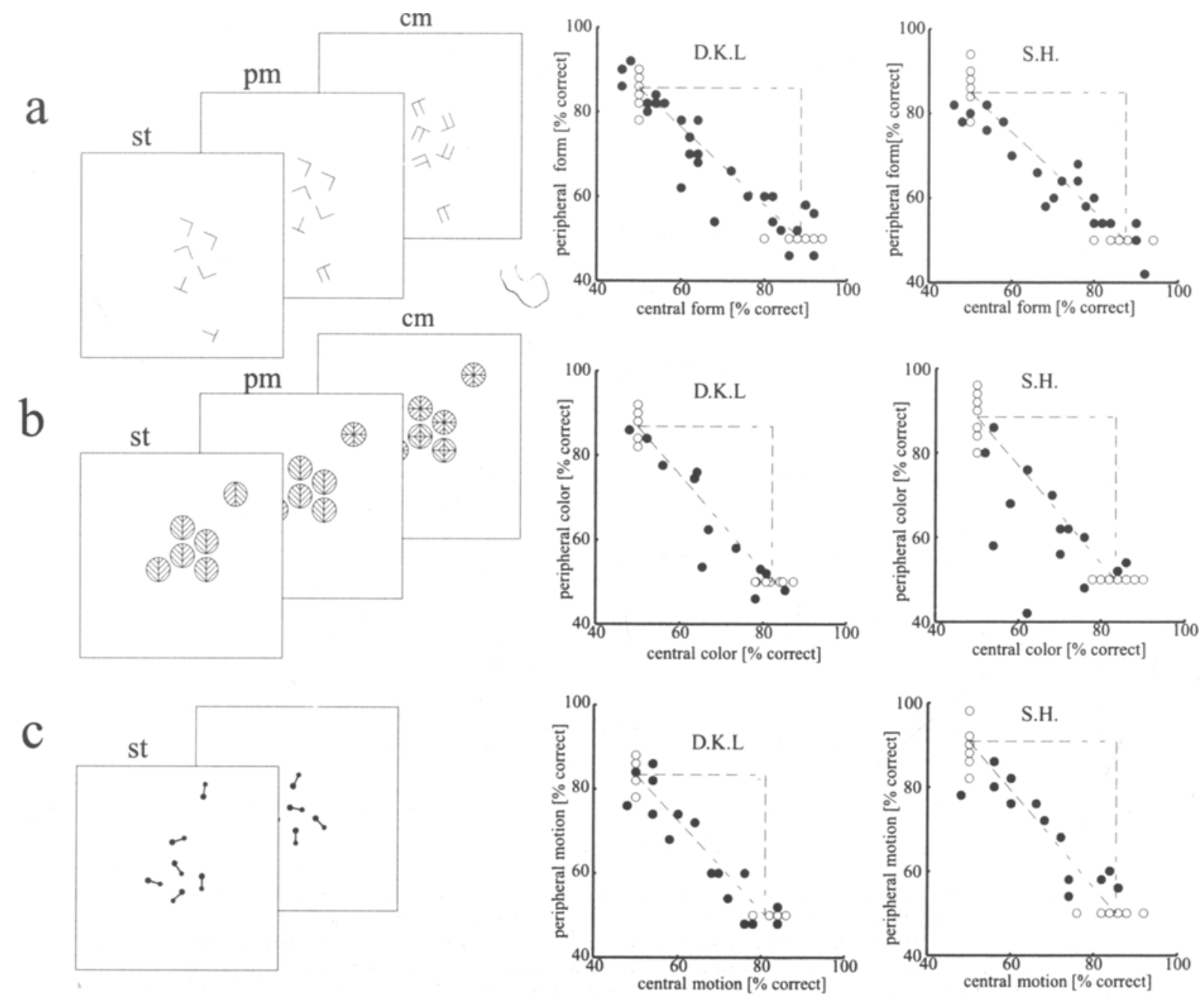

Figure 3. Displays and results for combinations of similar tasks. Stimulus and mask displays are not drawn to scale. Red/green color is indicated by hatching. Results are presented in the form of an attention operating characteristic (AOC), with center task performance on the horizontal axis and peripheral task performance on the vertical axis. Open circles indicate single-task and filled circles double-task performance. Each circle represents one block of 50 trials. Dashed lines indicate the theoretical extremes of the $A O C$. Subjects are identified by their initials (D.K.L. or S.H.). (a) Central and peripheral form discrimination. The stimulus display (st) is followed by a peripheral mask (pm) and a central mask (cm). (b) Central and peripheral color discrimination. The stimulus display (st) is followed by a peripheral mask (pm) and a central mask ( $\mathrm{cm}$ ). (c) Central and peripheral form discrimination. The stimulus display (st) is not masked, but the peripheral element is presented for less time than the central elements. In all three experiments, doubletask performance follows the lower extreme of the AOC, indicating that optimal performance of either task requires full attention.

some of the available attention was not allocated to either task). This aspect of the results is discussed further below. A contingency analysis was performed after the blocks for each subject and task combination were pooled to determine whether subjects had maintained a stable division of attention. No significant $(p<.05)$ response correlation was found. Pooled results from all three task combinations are shown in Figure 7.

It is clear from inspection of Figure 3 that all task combinations were characterized by a linear or nearly linear performance tradeoff. This can be confirmed by generating a family of theoretical AOC curves and computing the likelihood that a given curve will produce the observed results. We carried out such an analysis and found the likeliest values of the "attentional demand" parameter $\alpha$ to range from 0.98 to 1.00 for all tasks and observers (see Method section for definition of $\alpha$ ). Of course, the individual block results are expected to scatter somewhat simply because of the finite number of trials per block. In general, the observed scatter was not significantly different from the scatter expected from binomial sampling of a linear tradeoff. This was true for all observers and task combinations ( $\chi^{2}$ test, $p<.0001$ ), except the colorcolor combination of Observer S.H. (who performed exceptionally poorly on two blocks). However, individual block results tend to fall somewhat more frequently below than above the linear tradeoff line. For Observers D.K.L. and S.H., the average distance of individual block 
results from the linear tradeoff line is $-0.91 \pm 0.49$ and $-1.84 \pm 0.74$ percentage points, respectively (mean \pm standard error; negative values indicate positions below the line). This small departure from strict linearity was weakly significant $(t$ test, $p<.05)$.

\section{Dissimilar Task Combinations}

A second series of experiments established concurrent performance of dissimilar tasks. Four task combinations were investigated: central discrimination of color combined with peripheral discrimination of form or motion, and central discrimination of motion combined with peripheral discrimination of form or color.

Results are shown in Figures 4 and 5. Each subject performed between 29 and 35 blocks of 50 trials on each task combination (average $\approx 33$ blocks). As was the case for similar task combinations, double-task performance was generally inferior to single-task performance. Whenever double-task performance of one task approached the single-task level, double-task performance of the other task approached chance. However, in many blocks of trials, double-task performance was well below the linear tradeoff line, suggesting that subjects frequently failed to efficiently allocate attention. A contingency analysis was performed after the blocks for each subject and task combination were pooled, but no significant $(p<.05)$ response correlation was found. Pooled results from all four dissimilar task combinations are shown in Figure 7.

As is the case with similar task combinations, the results from dissimilar task combinations are likely to reflect a linear performance tradeoff. The most likely values of $\alpha$ range from 0.95 to 1.00 for all tasks and observers. The distribution of individual block results was not significantly different from the distribution expected from binomial sampling of a linear tradeoff $\left(\chi^{2}\right.$ test, $\left.p<.0001\right)$ except for the color-motion combination of Observer S.H. and the motion-color combination of Observer D.K.L. In both cases, the departure from the expected distribution was due to exceptionally poor performance in a few blocks of trials. However, individual block results fall more frequently below than above the linear tradeoff line. The average distance of individual block results from the linear tradeoff line was significantly less than zero: $-2.48 \pm 0.79$ percentage points for Observer D.K.L. and $-2.92 \pm 0.71$ percentage points for Observer S.H. ( $t$ test, $p<.01$ ).

\section{Contingency Analysis of Pooled Results}

As mentioned, contingency analysis of data for individual subjects and task combinations revealed no significant response correlation, suggesting that subjects maintained a consistent division of attention during each
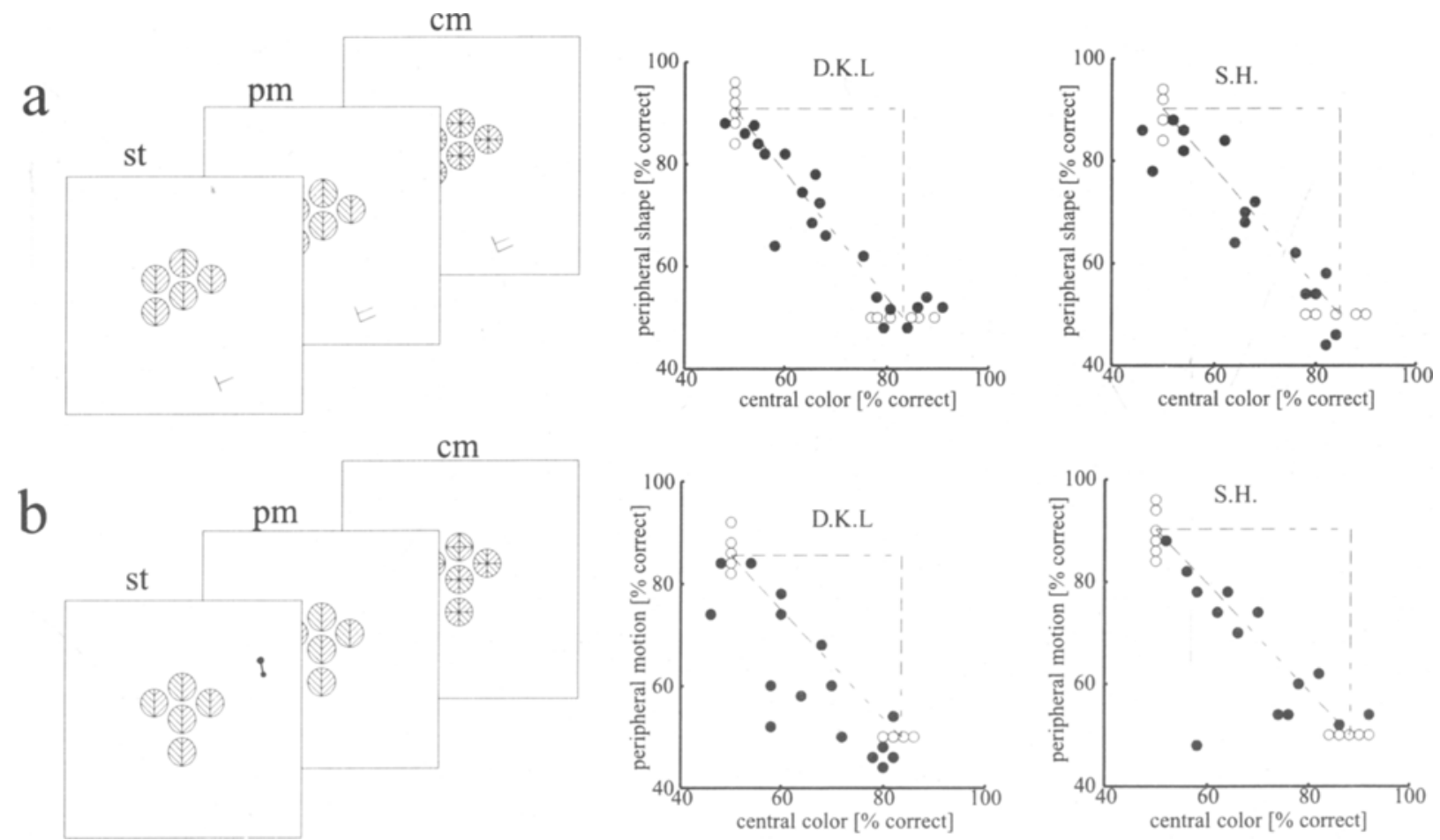

Figure 4. Displays and results for combinations of dissimilar tasks. See Figure 3 caption. (a) Central color and peripheral form discrimination. The stimulus display (st) is followed by a peripheral mask (pm) and a central mask (cm). (b) Central color and peripheral motion discrimination. The stimulus display (st) is followed by a peripheral mask (pm), and the peripheral element is presented for less time than the central elements. In both experiments, optimal performance of either task requires full attention. 

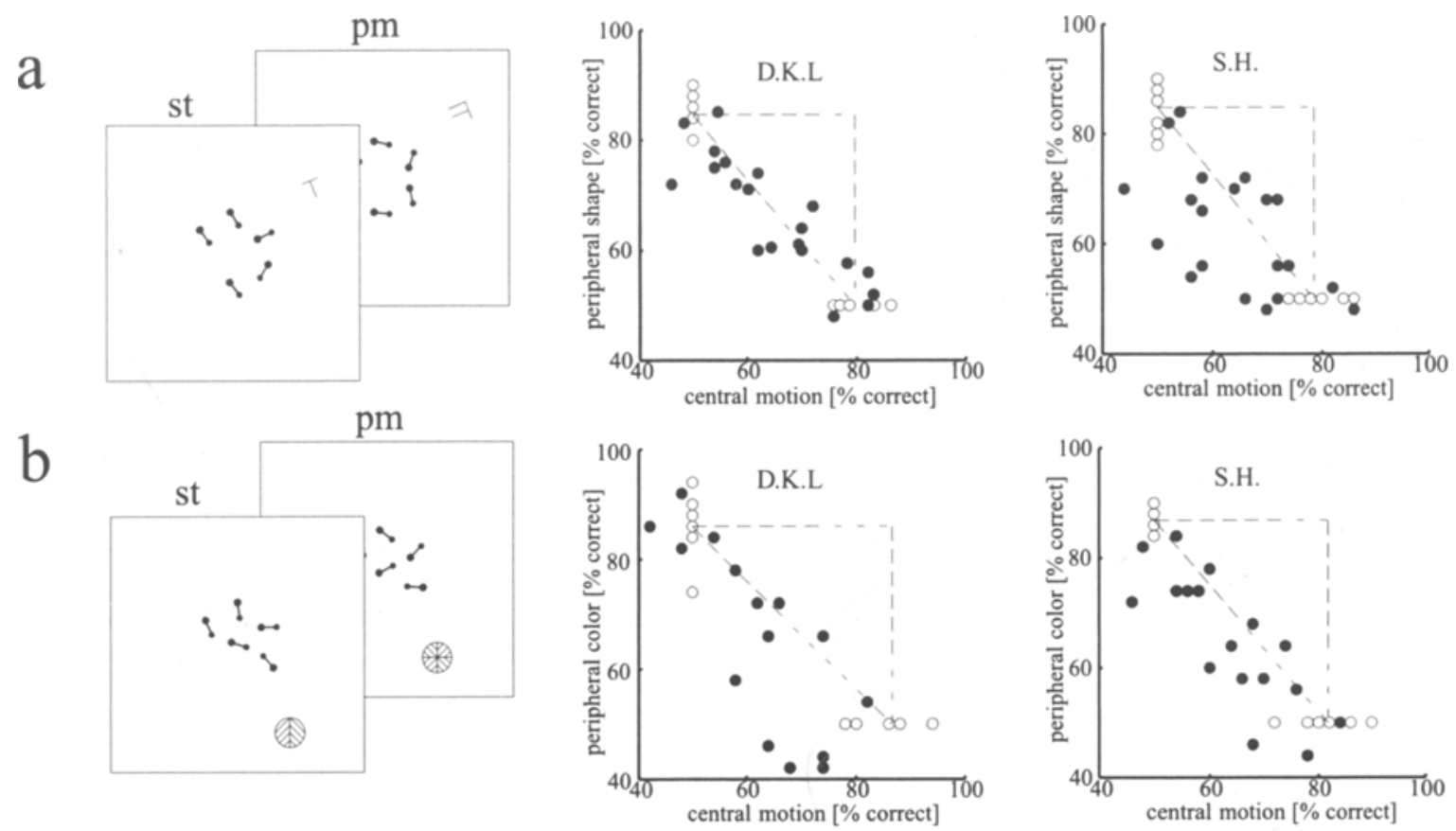

Figure 5. Displays and results for combinations of dissimilar tasks. See Figure 3 caption. (a) Central motion and peripheral form discrimination. The stimulus display (st) is followed by a peripheral mask (pm). (b) Central motion and peripheral color discrimination. The stimulus display (st) is followed by a peripheral mask (pm). In both experiments, optimal performance of either task requires full attention.

block of trials. To see whether a residual response correlation would reach significance for an even larger data set, we pooled the results of all experiments on similar and dissimilar task combinations. In doing so, we considered only blocks of trials in which double-task performance of both tasks was comparable (neither performance above $70 \%$ of single-task level). The rationale was that near the middle of the AOC curve (when attention is about equally divided between tasks and performance comparable), a response correlation is more likely than at the ends of the AOC curve (when attention is directed mostly at one task and performance is disparate). Thus, by limiting the analysis to the middle of the AOC curve, we maximized the chances of observing a response correlation.

To show how responses to one task depend on responses to the other task, we plotted percentage correct when subjects failed on the other task against percentage correct when subjects succeeded on the other task (Figure 6). As expected, performance was slightly better when subjects failed on the other task. This was true for both similar and dissimilar task combinations (3,950 and 4,450 trials, respectively). On average, the difference in performance was less than 3 percentage points, large enough to be significant ( $\chi^{2}$ test, $p<.005$ ) in the pooled data sets but too small to reach significance in individual data sets.

Model calculations (see Method section) show that a negative response correlation of this small magnitude is expected if attention focuses completely on one task or the other in $\approx 15 \%$ of the trials but is divided equally in the remaining $\approx 85 \%$ of the trials (Figure 6 ). Another way of obtaining such a correlation is to divide attention on all trials, but to vary the exact division, favoring sometimes one task and sometimes another. The necessary degree of variation depends on the form of the PRF - specifically, on the parameter $\beta$. For $\beta=1$, the division of attention would have to vary between approximately $30 \% / 70 \%$ and $70 \% / 30 \%$ (if both are equally likely), for $\beta=2$ it would have to vary between approximately $39 \% / 61 \%$ and $61 \% / 39 \%$, and for $\beta=3$ the variation would have to be approximately $43 \% / 57 \%$ to $57 \% / 43 \%$.

\section{Earlier and Later Sessions}

Pooled results for all task combinations are shown in Figure 7. The distribution of double-task outcomes is rather broad, especially for dissimilar task combinations, and includes many blocks of trials well below the linear tradeoff line, in which subjects failed to perform well on either task. This poor performance is puzzling, since subjects could have done better by simply ignoring one of the two tasks. The most plausible explanation of these data is that subjects failed to allocate attention to either task, perhaps because they were overwhelmed by the complexity of the double-task situation.

This interpretation is strengthened when the results of earlier and later sessions on any given task combination are considered separately (i.e., sessions in the first and second half of all sessions on any particular task combi- 


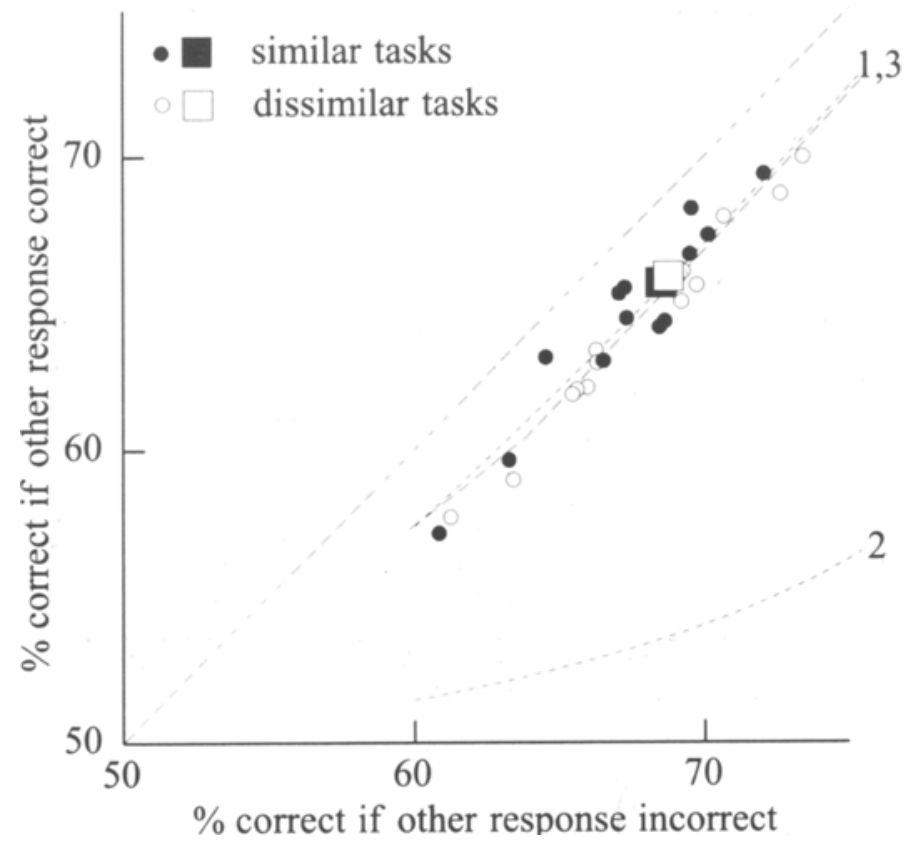

Figure 6. Contingency analysis of pooled results. For a given task, we computed performance separately for trials in which subjects responded correctly and incorrectly on the other task, and plotted the two values against each other. Open circles show results for similar task combinations (the open square represents the mean), and filled circles show results for dissimilar task combinations (the filled square represents the mean). On average, performance was about 3 percentage points lower when the other response was correct. For comparison, we show the expected contingencies if in $15 \%$ of the trials attention had focused on one task or the other instead of being divided (1), if this had happened in all trials (2), and if attention had been divided in all trials but the exact division varied from trial to trial (sometimes $30 \% / 70 \%$ and sometimes $70 \% / 30 \%$ ) (3).

nation). Blocks of trials in which subjects failed on both tasks occurred almost exclusively in the earlier sessions. In later sessions, subjects were consistently better, apparently because they had learned to efficiently allocate attention to one or both tasks so that no attention was wasted. Considering only data from later sessions, the distribution of individual block results does not depart significantly from the linear tradeoff line for either similar or dissimilar task combinations ( $\chi^{2}$ test, $p<.0001$ ). The average distance from the linear tradeoff line was $-0.26 \pm 0.98$ percentage points for similar and $-0.23 \pm$ 0.88 percentage points for dissimilar task combinations. Neither value was significantly different from zero ( $t$ test, $p<.0001$ ).

\section{DISCUSSION}

Attention is widely considered to be first and foremost a means of controlling the flow of information between different levels of processing. Stimuli selected by attention gain access to higher levels of processing that include recognition, awareness, memory, and the generation of voluntary responses, whereas stimuli rejected by attention are denied such access. This contrasts with lower levels of processing, which represent all stimuli indiscriminately, whether selected by attention or not. Lower processing levels are presumed to have spatially parallel architecture and to be free of capacity limitations ("early vision"). A strong implication of this view is that effects of attention are more evident at higher than at lower levels of processing (e.g., Broadbent, 1971; Kahneman, 1973; Kahneman \& Treisman, 1984; Nakayama \& Joseph, 1998; Neisser, 1967; Pashler, 1997).

A somewhat different possibility that has recently been gaining ground is that attention affects all levels of processing. In this view, attention has the direct consequence of enhancing or attenuating responses at lower levels of processing and the indirect consequence of facilitating access to higher levels of processing. This view is easier to reconcile with the neurophysiological finding that attention modulates neural responses throughout visual cortex (for a review, see Desimone \& Duncan, 1995; see also Maunsell, 1995). Attention has been observed to modulate visual responses in inferotemporal cortex (Chelazzi, Miller, Duncan, \& Desimone, 1993; Miller, Li, \& Desimone, 1993; Ungerleider, 1995), in extrastriate cor- 


\section{a. Similar tasks}
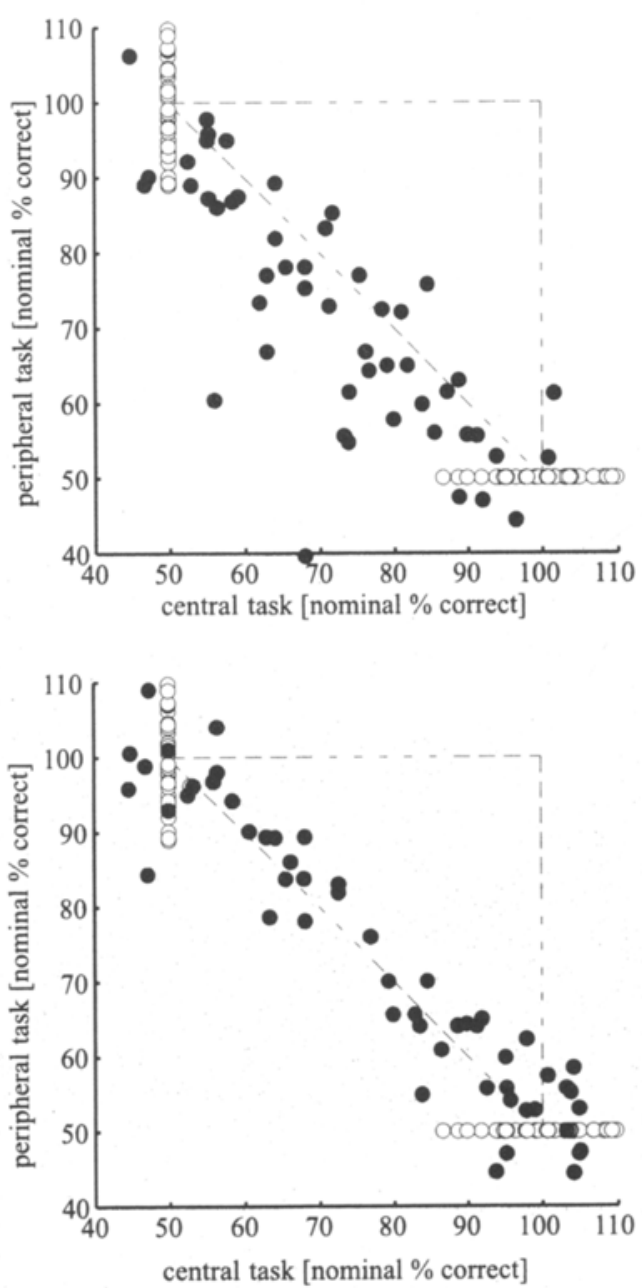

b. Dissimilar tasks
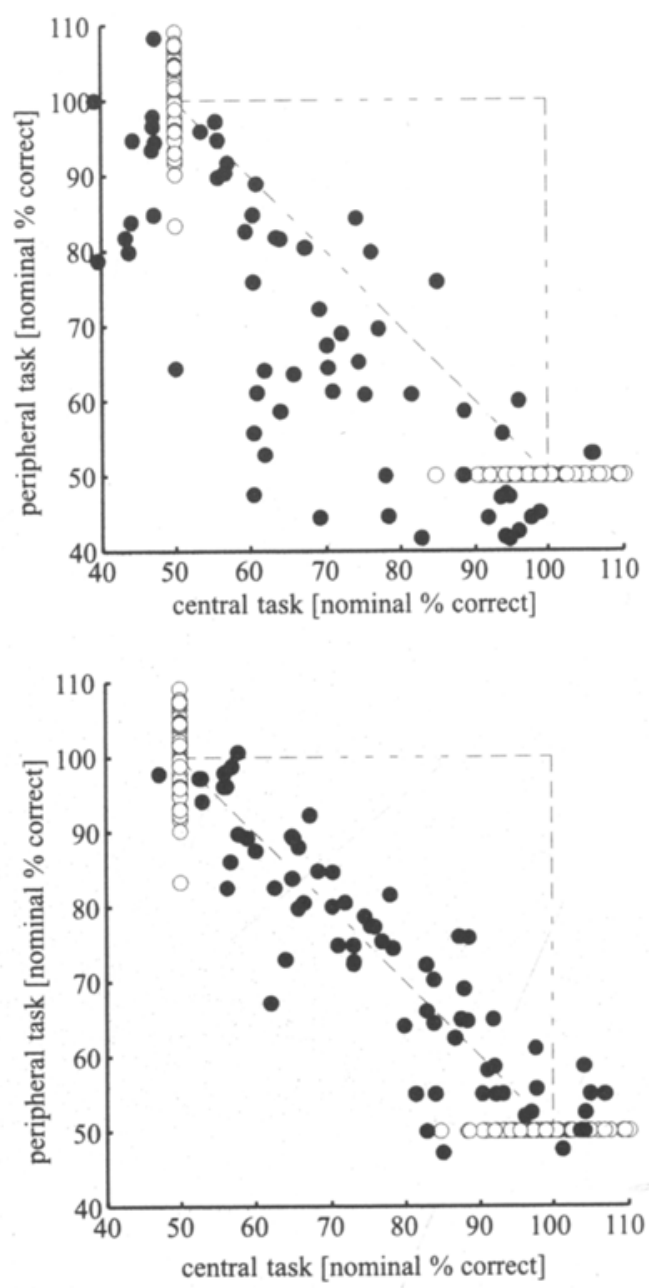

Figure 7. Pooled results from earlier and later sessions with any given task combination, both subjects. See Figure 3 caption. Most block results are well below the linear tradeoff line stem from earlier. During later sessions, almost all block results clustered near the linear tradeoff line, suggesting that subjects learned to allocate attention efficiently. "Nominal percentage correct" values were computed separately for each task by mapping the interval from chance performance to average single-task performance onto the interval $(50 \%, 100 \%)$.

tex (Moran \& Desimone, 1985; Motter, 1994; Treue \& Maunsell, 1996), and to some extent even in striate cortex (Motter, 1993). Another fact that points to a modulation of lower processing levels is that in many cases attention enhances stimulus discriminability $d^{\prime}$, suggesting an altered sensory representation (see, e.g., Bonnel \& Miller, 1994; Braun, 1994; Downing, 1988; Lee, Koch, \& Braun, 1997a, 1997b; Nakayama \& Mackeben, 1989).

An important implication of this modified view is that certain stimuli may reach higher levels of processing even without being selected by attention: The necessary and sufficient condition for access to higher levels is not selection by attention but simply a suitably strong response at lower levels. Of course, most stimuli elicit a suitable response only as a result of being selected by attention.
However, when a visual scene contains stimuli that are "salient" (Koch \& Ullman, 1985; Robinson \& Petersen, 1992), observers are subjectively aware of, and able to respond to, such stimuli even when attention is engaged by a demanding task elsewhere in the scene (Braun, 1994; Braun \& Julesz, 1998; Braun \& Sagi, 1990). Thus it would appear that "salient" stimuli elicit a suitably strong response to reach higher levels of processing even without being selected by attention.

Its "limited capacity" is the characteristic of attention that is most central to the present study. Although it is well established that only a limited number of stimuli can benefit from attention at any one time, it is far from evident why this should be so (Pashler, 1997, pp. $226 \mathrm{ff}$.). A reason often cited is that the limitation does not reflect 
so much attention but rather the higher levels of processing to which attention provides access (e.g., Kinsbourne, 1981). In this view, attention can (and occasionally does) select a large number of visual stimuli, but the results are counterproductive: Visual performance suffers because higher levels of processing are equipped to handle only a few stimuli at a time. An alternative possibility is that the limitation is inherent in the process of selection, which may be so constituted as to allow only a certain number of stimuli to be selected at any one time. Perhaps selection involves the formation of visual objects and is limited by Gestalt rules (see, e.g., Kanwisher \& Driver, 1992). Although the present study does not directly address the reason for the limited capacity of attention, its results have some bearing on the matter.

\section{Choice of Paradigm}

Over the years, various paradigms have been employed to measure interference between concurrent visual tasks. In many cases, an important consideration was the ability to distinguish attentional limitations from the wellknown limitations of short-term memory (e.g., Potter, 1976; Sperling, 1960). For example, one can compare discrimination of two stimuli that are presented either simultaneously or successively. Since memory limitations are expected with both modes of presentation but attentional limitations only with simultaneous presentation, the comparison should distinguish between limitations of memory and limitations of attention (Duncan, 1980; Duncan et al., 1994; Fisher, 1984; Kleiss \& Lane, 1986; Shiffrin \& Gardner, 1972; Ward et al., 1996).

Another way of identifying attentional interference between concurrent discriminations has been used in experiments involving same or different visual objects (Duncan, 1984; Treisman, 1969; Vecera \& Farah, 1994). In these experiments, observers discriminate either two attributes of one object (ignoring the other object) or one attribute of each object (ignoring the other attributes). Interference is found only in the latter case-the discrimination of one attribute of each object -leaving little doubt that interference originates at the visual level (i.e., the level of attention). Incidentally, these results also highlight the intimate connection between attentional selection and visual objects (Kanwisher \& Driver, 1992).

Besides memory and attention, yet another potential source of interference between concurrent tasks is response selection (Johnston, McCann, \& Remington, 1995; Pashler, 1991, 1994). It is readily distinguishable from attentional interference, since it is independent of the exact timing of stimulus presentation, occurs even when two tasks concern different modalities, and is highly sensitive to the characteristics of the response (e.g., order, timing, complexity). Another difference may be that the resources of response selection cannot be shared in a graded fashion between two concurrent tasks (Pashler, 1997, pp. 311 ff.). Indeed, interference at the response level may involve subcortical rather than cortical structures (Ivry, Franz, Kingstone, \& Johnston, 1998; Pashler,
Luck, O'Brien, Mangun, \& Gazzaniga, 1995). These factors have led Johnston and colleagues to argue for two distinct types of attention - "input attention" and "central attention"- which produce interference at different levels (Johnston et al., 1995).

The present experiments were designed to measure task interference at the level of visual attention. Central and peripheral targets formed two distinct visual objects, which were presented simultaneously and masked, while responses were unspeeded. Responses involved one or two binary choices, well below the capacity of visual short-term memory (see, e.g., Luck \& Vogel, 1997). Control experiments have shown that interference disappears when central and peripheral targets appear successively rather than simultaneously, and that interference is independent of response order (Braun \& Julesz, 1992, 1998). This indicates that any interference obtained with this paradigm does not reflect limitations at the level of memory or response selection.

The most surprising finding with this paradigm is that widely disparate outcomes are obtained with seemingly similar task combinations. As discussed below, some task combinations produce little or no interference, whereas other, similar task combinations produce severe interference (Braun, 1994; Braun \& Julesz, 1998). Thus, the linear tradeoff curves reported here are not necessarily typical. For example, there is little or no interference (1) between central form discrimination (i.e., the task used in the present study) and peripheral localization of a uniquely oriented Gabor element ("pop-out"), or (2) between central form discrimination and two peripheral hue discriminations. In both cases, the peripheral task is carried out comparably well with and without the central task. In other instances with the same outcome, the peripheral tasks involved up to four binary choices, which demonstrates among other things that the task combinations studied here fall well within the capacity of short-term memory.

\section{Attentional Capacity Is Divisible}

Our results show that observers divide attention between tasks in almost every trial, rather than simply allocating attention sometimes to one task and sometimes to the other. This follows from the relatively small response correlation we observed: The average accuracy of one response was only about 3 percentage points better when the other response was incorrect rather than correct. The most likely cause of this small correlation is some degree of variability in the division of attention. Depending on the form of the PRFs, and especially the value of $\beta$, a relatively modest degree of variability would be sufficient to account for the observed response correlation (for $\beta=1,2,3$, the division of attention would have to vary by approximately $\pm 20 \%, \pm 11 \%$, or $\pm 7 \%$, respectively).

Of course, a major unsolved question is how the division of attention is accomplished. Two possibilities are evident. One is that attention concurrently "selects" the 
stimuli relevant to both tasks, but does so only "partially." The how and why of such a "partial selection" is far from obvious. The other possibility is that attention shifts from one task to another at some point during the trial. In this case only one set of stimuli is selected at any one moment, but each set is selected for only about half the time. The problem with this possibility is that attention would have to shift essentially without delay between the two sets of stimuli. Current evidence does not rule out either of these possibilities (Braun, 1998; but see Duncan et al., 1994; Ward et al., 1996). When subjects are as highly practiced as they were in the present study, a "rapid shift" certainly seems no less likely than a "partial selection."

\section{Attentional Capacity Is Undifferentiated}

The outcome of the present study could hardly have been clearer. Both similar and dissimilar task combinations resulted in an almost exactly linear performance tradeoff. This was true for three similar tasks combinations that involved two discriminations of form (T vs. L), color (red-green vs. green-red), and motion (clockwise vs. counterclockwise), respectively, and for four dissimilar combinations that involved discriminations of color and form, color and motion, or motion and form. A more detailed analysis showed only minor differences between similar and dissimilar combinations. One of these differences concerned the first session with each task combination, during which observers sometimes performed poorly on both tasks. This happened more often with dissimilar than with similar task combinations, suggesting that the initial difficulty of dividing attention may have been greater for dissimilar than for similar tasks. Another minor difference was the distribution of the most likely tradeoff curves to account for the observed concurrent task performance. For dissimilar task combinations, this distribution was narrower, and thus the evidence for a strictly linear tradeoff was somewhat better than that for similar task combinations.

We conclude that similar and dissimilar tasks draw on exactly the same attentional capacity-in other words, that attentional capacity is entirely undifferentiated. Although the same conclusion has been reached in previous studies (Duncan, 1993; Duncan \& Nimmo-Smith, 1996), we have considerably strengthened the evidence for it. By virtue of using tasks with high attentional cost, and by quantifying this cost, our paradigm was sufficiently sensitive to reveal intermediate outcomes (i.e., a partly differentiated capacity). The fact that the actual outcome was extreme, rather than intermediate, must therefore count as highly significant. Our results do not support the suggestion (Duncan \& Nimmo-Smith, 1996) that the discrimination of color enjoys a special status. We observed the same tradeoff curves for task combinations with and without color discrimination. Color discrimination probably yielded such different results for Duncan and colleagues because the particular discrimination they used carries little or no attentional cost (Braun \& Julesz, 1998).

If a price had to be paid for the sensitivity of our paradigm, this price was the somewhat complex nature of our discrimination tasks. Two aspects of the design were responsible for the high attentional cost of our tasks. The first aspect was positional variability. Although this is not often emphasized, a long roster of divided attention studies shows that performance decrements (i.e., attentional costs) increase with positional variability (Braun \& Sagi, 1991; Duncan, 1980, 1993; Duncan et al., 1994; Shiffrin \& Gardner, 1972). In the present case, positional variability was achieved for central tasks by presenting the five central targets in 35 distinct configurations (not counting rotational states), and for peripheral tasks by presenting the peripheral target at one of eight possible positions. The second aspect of the design that ensured high attentional cost was a requirement for joint discrimination of form (or color, or motion) and position. To report the form of a (randomly rotated) $\mathrm{T}$ or $\mathrm{L}$, the observer has to discriminate both orientation and position of two component lines. Similarly, to distinguish redgreen and green-red disks, the observer has to discriminate both the color and the position of two half-disks, and to distinguish clockwise and counterclockwise motion, he/she has to discriminate both the direction of motion and the position of two terminal points.

Thus, the discriminations used here are not "pure" discriminations of form, color, and motion, but are always "mixed" discriminations of form, color, motion, and position. It can be argued that this fact limits the generality of our conciusions, since it is possible that mixed discriminations engage different attentional capacities than do pure discriminations. To address this question, it is necessary to compare similar and dissimilar combinations of pure discrimination tasks. Of course, the attentional cost of such discriminations will be lower, and our ability to characterize their PRFs correspondingly poorer. Nevertheless, such experiments are feasible and are currently under way.

If attentional capacity is undifferentiated, this fact may provide some clues as to the nature of this capacity. As mentioned, it has never been evident what limits attentional capacity in the first place. Many writers have assumed that the limitation has nothing to do with attention proper-that is, the process of selecting some stimuli and rejecting others-but that it is a limitation at the level of classification or recognition, which can deal with only a limited amount of information (e.g., Mozer, 1991). However, classification and recognition presumably involve different cortical sites, depending on the stimulus being recognized or classified, and it is difficult to see why all of these sites should be subject to the same capacity limitation. In other words, if the limitation arises at higher levels of processing, one would expect attentional capacity to be at least partially differentiated. It is easier to understand the results of the present study if ca- 
pacity limitations arise from the step of selection itself. If attention can select only a limited number of stimuli at any one time, it follows that attentional capacity will be as undifferentiated as we have observed. An important consequence of this is that cortical sites representing different stimulus dimensions will be tightly coupled by attention, so that any stimulus selected at one site will also be selected at the others (Duncan, Humphreys, \& Ward, 1997). We conclude that the present results are more consistent with capacity limitations of selection than of subsequent levels of processing.

None of these considerations address the more fundamental issue as to whether capacity limitations have a functional role or simply reflect physical limitations. Our guess is that capacity limitations serve a useful function in connection with the Gestalt principles governing the formation of "visual objects." We surmise that selection involves an interaction between attentional and grouping processes, and that the result of this interaction is necessarily a single "attended" visual object. However, this remains mere speculation.

Finally, it is worth mentioning that different sensory modalities seem to draw on different attentional capacities. Concurrent words or syllables are more readily discriminated when they are presented in different modalities (e.g., visually and aurally) rather than in the same modality (Duncan, Martens, \& Ward, 1997; Treisman \& Davies, 1973). Similarly, an attentionally demanding vi- sual tracking task can be carried out concurrently with an auditory, but not a visual, word recognition task (Wen, Koch, \& Braun, 1995). Although instances of comparable inter- and intramodal interference have been reported as well (Lindsay, Taylor, \& Forbes, 1968; Massaro \& Warner, 1977), these seem to be more in the nature of exceptions to the rule (Pashler, 1997, pp. 157ff.).

\section{Attentional Cost of Discrimination}

The paradigm of the present study has also been used in two previous studies to measure the attentional cost of discrimination tasks (Braun, 1994; Braun \& Julesz, 1998). When one compares the results, one is struck by large differences in the attention cost of different tasks. One way to conduct this comparison is to use the parameter $\alpha$ as a measure of attentional cost - that is, the fraction of attention at which peripheral performance reaches ceiling. After reanalyzing the results of previous studies accordingly, one obtains $\alpha \approx 0.3$ for the discrimination of triangular and circular forms, $\alpha \approx 0.2$ for the discrimination of subtle hues, and $\alpha \approx 0.25$ for the simultaneous discrimination of color and orientation (Figure 8). Of course, $\alpha \approx 1.0$ for all discriminations used in the present study.

Why this large difference in attentional cost? The tasks of the present study are certainly not more "demanding" than those of previous studies, inasmuch as they were performed comparably well at comparably long SOAs.

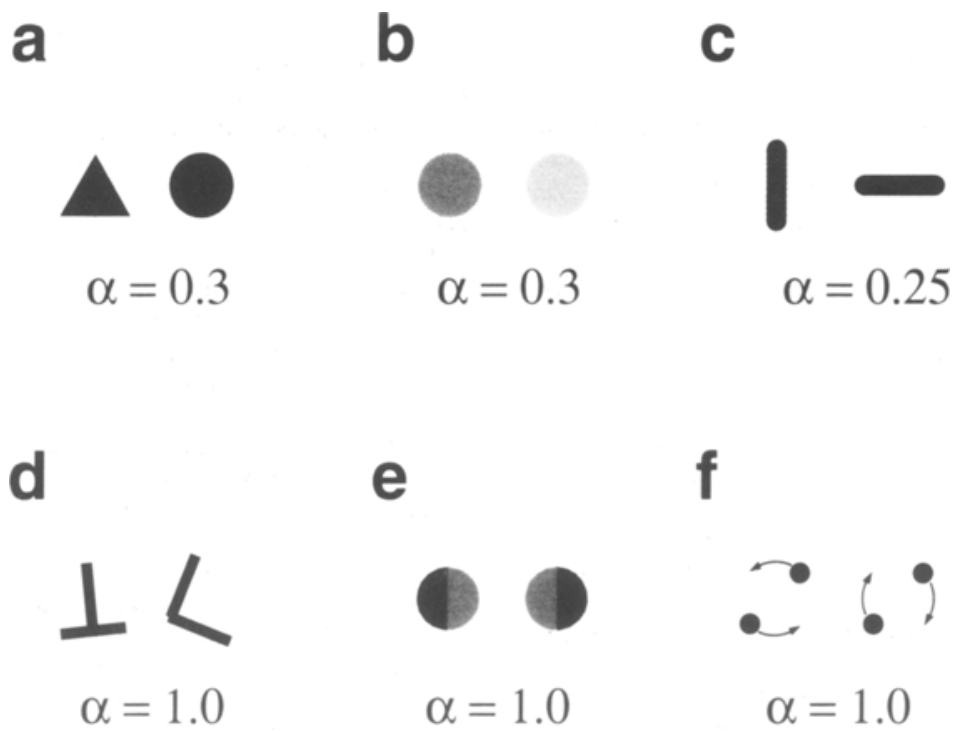

Figure 8. Attentional cost of discrimination tasks. Comparison of six discrimination tasks whose attentional cost was measured with the same paradigm (i.e., by engaging attention with a letter discrimination at display center). Attentional cost is expressed in terms of the parameter $\alpha$ (see Figure 2). (a) Discrimination of form (triangular/circular; Braun, 1994). (b) Discrimination of hue (orange/pink and turquoise/green; see Figure 2). (c) Simultaneous discrimination of orientation (horizontal/vertical) and color (red/green/blue/ yellow; Braun \& Julesz, 1998). (d) Discrimination of letter form (rotated $T$ or L). (e) Discrimination of coloring of bisected disks (red-green/green-red). (f) Discrimination of sense of rotation (clockwise/counterclockwise). 
The three tasks used here were performed between $82 \%$ and $90 \%$ correct at SOAs between 60 and $100 \mathrm{msec}$, and the three tasks studied previously were performed between $85 \%$ and $91 \%$ correct at SOAs between 72 and $126 \mathrm{msec}$. One possibility is that the present tasks are more "complex" than those used previously, in that they involve the discrimination of two target components (i.e., two line elements, two half-disks, or two terminal points). Another possibility is that the increased attentional cost is due to the need to jointly discriminate attributes and their positions (i.e., the orientation and position of two lines, the color and position of two half-disks, or the motion and position of two terminal points). The latter possibility is particularly attractive since recent singleunit recordings in area $\mathrm{V} 4$ of the awake macaque suggest that attention helps encode the relative position of stimulus attributes (Connor, Preddie, Gallant, \& Van Essen, 1997; Salinas \& Abbott, 1997). This is clearly an issue that deserves further study.

\section{Summary}

We investigated three types of tasks with high attentional costs and quantified the extent to which they interfered when observers attempted to perform them concurrently. We found that similar and dissimilar task combinations resulted in exactly the same degree of interference. This shows that all tasks investigated here engaged precisely the same attentional capacity, strongly suggesting that there is only one such capacity. In other words, attentional capacity is undifferentiated.

\section{REFERENCES}

AllPort, D. A. (1971). Parallel encoding within and between elementary stimulus dimensions. Perception \& Psychophysics, 10, 104-108.

Ben-Av, M. B., SAGI, D., \& BraUn, J. (1992). Visual attention and perceptual grouping. Perception \& Psychophysics, 52, 277-294.

BoNNEL, A-M., \& Miller, J. (1994). Attentional effects on concurrent psychophysical discriminations: Investigations of a sample size model. Perception \& Psychophysics, 55, 162-179.

Bonnel, A-M., \& Prinzmetal, W. (1998). Dividing attention between the color and the shape of objects. Perception \& Psychophysics, 60, 113-124.

Bonnel, A-M., Stein, J-F., \& BertuCCi, P. (1992). Does attention modulate the perception of luminance changes? Quarterly Journal of Experimental Psychology, 44A, 601-626.

BRAUN, J. (1994). Visual search among items of different salience: Removal of visual attention mimics a lesion in extrastriate area V4. Journal of Neuroscience, 14, 554-567.

Braun, J. (1998). Vision and attention: The role of training. Nature, 393, 424-425.

Braun, J., \& Julesz, B. (1992, November). Early vision: Dichotomous or continuous? Paper presented at the annual meeting of the Psychonomic Society, St. Louis.

Braun, J., \& Julesz, B. (1998). Withdrawing attention at little or no cost: Detection and discrimination tasks. Perception \& Psychophysics, 60, 1-23.

BraUn, J., \& SAGI, D. (1990). Vision outside the focus of attention. Perception \& Psychophysics, 48, 45-58.

Braun, J., \& SAGI, D. (1991). Texture-based tasks are little affected by a second task which requires peripheral or central attentive fixation. Perception, 20, 483-500.

Broadbent, D. E. (1971). Decision and stress. London: Academic Press.
Chelazzi, L., Miller, E. K., Duncan, J., \& Desimone, R. (1993). A neural basis for visual search in inferior temporal cortex. Nature, $\mathbf{3 6 3}$, 345-347.

Connor, C. E., Preddie, D. C., Gallant, J. L., \& Van Essen, D. C. (1997). Spatial attention effects in macaque area V4. Journal of Neuroscience, 17, 3201-3214.

Corbetta, M., Miezin, F. M., Dobmeyer, S., Shllman, G. L., \& PeTERSEN, S. E. (1990). Selective attention modulates neural processing of shape, color, and velocity in humans. Science, 248, 1556-1559.

Corbetta, M., Shulman, G. L., Miezin, M., \& Petersen, S. E. (1995). Superior parietal cortex activation during spatial attention shifts and visual feature conjunction. Science, 270, 802-805.

Desimone, R., \& DunCan, J. (1995). Neural mechanisms of selective visual attention. Annual Review of Neuroscience, 18, 193-222.

DowNING, C. J. (1988). Expectancy and visual-spatial attention: Effects on perceptual quality. Journal of Experimental Psychology: Human Perception \& Performance, 14, 188-202.

DunCan, J. (1980). The locus of interference in the perception of simultaneous stimuli. Psychological Review, 87, 272-300.

DUNCAN, J. (1984). Selective attention and the organization of visual information. Journal of Experimental Psychology: General, 113, 501-517.

DUNCAN, J. (1993). Similarity between concurrent visual discriminations: Dimensions and objects. Perception \& Psychophysics, 54, 425-430.

DunCAN, J., Humphreys, G., \& WARD, R. (1997). Competitive brain activity in visual attention. Current Opinion in Neurobiology, 7, 255-261.

Duncan, J., Martens, S., \& Ward, R. (1997). Restricted attentional capacity within but not between sensory modalities. Nature, 387, 808-810.

DUNCAN, J., \& Nimmo-Smith, I. (1996). Objects and attributes in divided attention: Surface and boundary systems. Perception \& Psychophysics, 58, 1076-1084.

Duncan, J., Ward, R., \& ShapiRo, K. (1994). Direct measurement of attentional dwell time in human vision. Nature, 369, 313-315.

EnNs, J. T., \& Rensink, R. A. (1990). Influence of scene-based properties on visual search. Science, 247, 721-723.

Felleman, D. J., \& VAN Essen, D. C. (1991). Distributed hierarchical processing in the primate cerebral cortex. Cerebral Cortex, 1, 1-47.

FisHer, D. L. (1984). Central capacity limits in consistent mapping, v1sual search tasks: Capacity scanning in visual search. Cognitive Psychology, 16, 449-484.

ISENBERG, L., NisSEN, M. J., \& MARChak, L. C. (1990). Attentional processing and the independence of color and orientation. Journal of Experimental Psychology: Human Perception \& Performance, 16, 869-878.

IVry, R. B., Franz, E. A., Kingstone, A., \& Johnston, J. C. (1998). The psychological refractory period effect following callosotomy Uncoupling of lateralized response codes. Journal of Experimental Psychology' Human Perception \& Performance, 24, 463-480.

Johnston, J. C., MCCAnN, R. S., \& Remington, R. W. (1995). Chronometric evidence for two types of attention. Psychological Science, 6 , 365-369.

Johnston, J. C., Ruthruff, E., \& Monheit, M. (1997). Dependence by any other name smells just as sweet: Reply to van der Velde and van der Heijden (1997). Journal of Experimental Psychology. Human Perception \& Performance, 23, 1813-1818.

Joseph, J. S., Chun, M. M., \& NaKayama, K. (1997). Attentional requirements in a "preattentive" feature search. Nature, 387, 805-807.

Julesz, B. (1981). Textons, the elements of texture perception and their interactions. Nature, 290, 91-97.

JULESZ, B. (1984). Towards an axiomatic theory of preattentıve visıon. In G. M. Edelman, W. E. Gall, \& W. M. Cowan (Eds.), Dynamic aspects of neocortical function (pp. 585-612). Washıngton, DC: Neurosciences Research Foundation.

Kahneman, D. (1973). Attention and effort. Englewood Cliffs, NJ: Prentice-Hall.

Kahneman, D., \& Treisman, A. (1984). Changing views of attention and automaticity. In R. Parasuraman \& D. R. Davies (Eds.), Varieties of attention (pp. 29-61). New York: Academic Press.

KANWISHER, N., \& DrIVER, J. (1992). Objects, attributes, and visual attention: Which, what and where. Current Directions of Psychological Science, 1, 26-31. 
Kinsbourne, M. (1981). Single channel theory. In D. Holding (Ed.), Human skills (pp. 65-89). Chichester, U.K.. Wiley.

KLEISS, J. A., \& LANE, D. M. (1986). Locus and persistence of capacIty limitations in visual information processing. Journal of Experimental Psychology: Human Perception \& Performance, 12, 200-210.

Kосн, C., \& UlLman, S. (1985). Shifts in selective visual attention: Towards the underlying neural circuitry. Human Neurobiology, 4, 219227.

LEE, D. K., Кoch, C., \& Braun, J. (1997a). Attentional modulation of contrast masking. Investigative Ophthalmology \& Visual Science, 38, 5457.

LEE, D. K., KoCh, C., \& Braun, J. (1997b). Spatial visıon thresholds in the near absence of attention. Vision Research, 37, 2409-2418.

LindSAY, P. H., TAYLOR, M M., \& Forbes, S. M. (1968). Attention and multıdımensional discrimination. Perception \& Psychophysics, 4 , $113-117$

LuCK, S. J., \& VoGEL, E. K. (1997). The capacity of visual working memory for features and conjunctions, Nature, 390, 279-281.

MASSARO, D. W., \& WARNER, D. S. (1997). Dividing attention between auditory and visual perception. Perception \& Psychophysics, 21, 569571 .

MAUNSELL, J. H. R. (1995). The brain's visual world-Representation of visual targets in cerebral cortex. Science, 270, 764-769

Mil.ter, E. K., LI, L., \& Desimone, R. (1993). Activity of neurons in anterior inferıor temporal cortex durıng a short-term memory task. Journal of Neuroscience, 13, 1460-1478.

Monheit, M., \& Johnston, J. C. (1994). Spatial attention to arrays of multidimensional objects. Journal of Experimental Psychology. Human Perception \& Performance, 20, 691-708.

Moran, J., \& Desimone, R. (1985). Selective attention gates visual processing in the extrastriate cortex. Science, 229, 782-784.

MotreR, B. C. (1993). Focal attention produces spatially selective processing in visual cortical areas V1, V2, and V4 in the presence of competıng stimuli. Journal of Neurophvsiologv, 70, 909-919.

MOTTER, B. C. (1994). Neural correlates of attentive selection for color or lumınance in extrastriate area V4. Journal of Neuroscience, 14, 2178-2189.

Mozer, M. C. (1991). The perception of multiple objects: A connectionist approach. Cambridge, MA: MIT Press.

Nakayama, K, \& JosePh, J. (1998). In R. Parasuraman (Ed.), The attentive brain (pp. 279-298). Cambridge, MA. MIT Press.

NAKAYAMA, K.. \& MACKEBEN, M. (1989). Sustained and transient components of focal visual attention. Vision Research, 29, 1631-1647.

Navon, D., \& Gopher, D. (1979). On the economy of the human processing system. Psychological Review, 86, 214-255.

NeIsser, U. (1967). Cognitive psychology. New York: Appleton Century Crofts.

Nissen, M. J. (1985). Accessing features and objects: Is location specral? In M. I. Posner \& O. S. M. Marin (Eds.), Attention \& performance $X I$ (pp. 205-219). Hıllsdale, NJ. Erlbaum.

Norman, D. A.. \& Bobrow, D. G. (1975). On data-limited and resourcelimited processes. Cognitive Psvchologv, 7, 44-64.

PAshler, H. (1991). Shifting visual attention and selectung motor responses: Distinct attentional mechanisms. Journal of Experimental Psychology Human Perception \& Performance, 17, 1023-1040.

PASHLER, H. (1994). Dual-task interference in simple tasks-Data and theory, Psvchological Bulletin, 116, 220-244

PaShle. H. (1997). The psychology of attention. Cambridge, MA: MIT Press.

Pashler, H., Luck, S., O’Brien, S., Mangun, R., \& Gazzaniga, M. (1995). Sequential operation of disconnected cerebral hemispheres in "split-braı" patients. NeuroReport, 5, 2381-2384.
PotTer, M. (1976). Short-term conceptual memory for pictures. Journal of Experimental Psychology Learning, Memory, \& Cognition, 2, 509-521.

Robinson, D. L., \& Petersen, S. E. (1992). The pulvinar and visual salience. Trends in Neurosciences, 15, 127-132

Salinas, E., \& ABbott, L. F (1997). Invariant visual responses from attentional gain fields. Journal of Neurophysiology, 77, 3267-3272.

ShIFFrin, R. M., \& GARDNER, G. T. (1972). Visual processing capacity and attentional control. Journal of Experimental Psychology, 93, 78-82.

SPERLING, G. (1960). The information available in visual presentations. Psychological Monographs, 74, 1-29.

SPERLiNG, G., \& Dosher, B. (1986). Strategy and optimization in human information processing. In K. R. Boff, L. Kaufman, \& J. P Thomas (Eds.), Handbook of perception and human performance (pp. 1-65). New York: Wiley.

Sperling, G., \& Melchner, M. J. (1978). The attention operating characteristic: Some examples from visual search. Science, 202, 315-318.

Treisman, A. (1969). Strategies and models of selective attention. Psychological Review, 76, 282-299.

Treisman, A., \& Davies, A. (1973). Dividing attention to ear and eye. In S. Kornblum (Ed.), Attention and performance IV (pp. 101-117). New York: Academic Press.

Treisman, A., \& Gelade, G. (1980). A feature integration theory of attention. Cognitive Psychology, 12, 97-136.

Treisman, A., \& Gormican, S. (1988). Feature analysis in early vision: Evidence from search asymmetries. Psychological Review, 95, 15-48.

Treisman, A., \& Souther, J. (1985). Search asymmetry: A diagnostic for preattentive processing of separable features. Journal of Experimental Psychology: General, 114, 285-310.

Treue, S., \& MAUNSELl, J. H. R. (1996). Attentional modulation of visual motion processing in cortical areas MT and MST. Nature, 382 , 539-541.

UNGERLEIDER, L. G. (1995). Functional brain ımagıng studies of cortical mechanisms for memory. Science, 270, 769-775.

van der Velde, F., \& van der Heijden, A. H. C. (1997). On the statistical independence of color and shape in object identification. Journal of Experimental Psychology Human Perception \& Performance, 23, 1798-1812.

VAN Essen, D. C., \& Drury, H. A. (1997). Structural and functional analyses of human cerebral cortex Journal of Neuroscience, 17, 7079-7102

VAN Essen, D. C., \& Gallant, J. (1994). Neural mechanisms of form and motion processing in the primate visual system. Neuron, 13, 1-10.

VECERA, S., \& FARAH, M. J. (1994). Does visual attention select objects or locations? Journal of Experimental Psychology: General, 123, $146-160$

WARD, R., DUNCAN, J., \& ShaPIRO, K. (1996). The slow time-course of visual attention. Cognitive Psychology, 30, 79-109.

WARD, R., DunCaN, J., \& Shapiro, K. (1997). Effects of similarity, difficulty, and nontarget presentation on the time course of visual attention. Perception \& Psychophysics, 59, 593-600

WeN, J., Koch, C., \& Braun, J. (1995). Visual tracking of multiple moving-objects requires modality-specıfic attention. Investigative Ophthalmology \& Visual Science, 36, 900.

WolfE, J. M. (1994). Guided Search 2.0: A revised model of visual search. Psychonomic Bulletin \& Review, 1, 202-238.

(Manuscript recelved February 23, 1998; revision accepted for publication August 24, 1998.) 